\title{
Theneurobiology of posttraumatic stress disorder: dysfunction in the prefrontal-amygdala circuit?
}

\author{
Isabela Lobo ${ }^{1}$, Letícia de Oliveira ${ }^{1}$, Isabel A. David ${ }^{1}$, Mirtes G. Pereira ${ }^{1}$, Eliane Volchan ${ }^{2}$, Vanessa \\ Rocha-Rego $^{3}$, Ivan Figueira ${ }^{2}$ and Izabela Mocaiber ${ }^{1}$ \\ 1- Universidade Federal Fluminense, Niterói, RJ, Brazil \\ 2- Universidade Federal do Rio de Janeiro, Rio de Janeiro, RJ, Brazil \\ 3- University of London, London, LDN, UK
}

\begin{abstract}
Posttraumatic stress disorder (PTSD) is an anxiety disorder that can develop following exposure to a traumatic event, including terrifying or life-threatening situations such as sexual assault or natural disasters. The disorder is characterized by a reaction of intense fear, helplessness, or horror when the individual experiences, testifies about, or is faced with one or more events that involve death, severe wounds, or a threat to one's own or another's physical integrity. One of the most important symptoms of PTSD is the revival of the traumatic event, which has been interpreted as an inability to downregulate negative emotions. Neuroimaging studies that probed the ability to regulate emotions in healthy volunteers have found a pattern characterized by activation of the prefrontal cortex associated with a reduction in amygdala activity. This suggests an inhibitory prefrontal cortexamygdala circuit that underlies emotional regulation. The hypothesis that increased amygdala activation associated with PTSD results from dysfunction in the inhibitory mechanism exerted by the prefrontal cortex has been the topic of debate. The present review investigates the validity of dysfunction in the prefrontal-amygdala pathway in PTSD. The studies provide evidence that the amygdala and prefrontal cortex exhibit distinct activation patterns in PTSD, thus supporting the model of a dysfunctional circuit. Inconsistencies in the literature may be attributable to distinct PTSD subgroups, different experimental approaches, different contrasts employed in neuroimaging studies, and small sample sizes. Keywords: prefrontal cortex, amygdala, PTSD.
\end{abstract}

Received 8 February 2011; received in revised form 28 March 2011; accepted 1 April 2011. Available on line 10 October 2011

\section{Introduction}

The regulation of emotions has been defined as the conscious or unconscious strategies to maintain, increase, or decrease one or more components of the emotional response, including feelings, behaviors, and physiological responses involved in the construction of emotions (Gross, 1998, 2002; Ochsner \& Gross, 2005; Mauss,

Isabela Lobo, Leticia de Oliveira, Isabel A. David, and Mirtes G. Pereira, Departamento de Fisiologia e Farmacologia, Instituto Biomédico, Universidade Federal Fluminense, Brazil. Eliane Volchan, Programa de Neurobiologia, Instituto de Biofísica Carlos Chagas Filho, Universidade Federal do Rio de Janeiro, Brazil. Vanessa Rocha-Rego, Institute of Psychiatry, King's College London, University of London, UK. Ivan Figueira, Instituto de Psiquiatria, Universidade Federal do Rio de Janeiro, Brazil. Izabela Mocaiber, Departamento Interdisciplinar, Polo Universitário de Rio das Ostras, Universidade Federal Fluminense, Brazil. Correspondence regarding this article should be directed to: Izabela Mocaiber, Departamento Interdisciplinar de Rio das Ostras, Polo Universitário de Rio das Ostras / Universidade Federal Fluminense, Rua Recife, s/n, Jd. Bela Vista, Rio das Ostras - RJ, CEP 28.890-000, Brazil. Phone/Fax: +55 (22) 2760 0848. E-mail: mocaiber@vm.uff.br
Evers, Wilhelm, \& Gross, 2006). Emotional regulation is a fundamental skill for social interaction, directly influencing behavior and emotional expression (Lopes, Salovey, Cote, \& Beers, 2005; Mocaiber et al., 2010). Studies have shown that individual differences in the dimensions of positive affect traits (Oliveira et al., 2009), anxiety levels (Mauss, Wilhelm, \& Gross, 2003; Gillath, Bunge, Shaver, Wendelken, \& Mikulincer, 2005; Mocaiber et al., 2009), prosocial tendencies (Lopes et al., 2005), and hemispheric asymmetry activation profiles (Jackson et al., 2003) influence the ability to regulate emotions. Moreover, some mental disorders are partially characterized by the persistence of negative emotions in which the inability to regulate them appears to play an important role in the development and maintenance of such disorders (Campbell-Sills, Barlow, Brown, \& Hofmann, 2006).

Several studies have been conducted to understand the neural substrates of emotional regulation. Researchers have proposed that the brain circuits associated with emotional regulation include regions of the prefrontal cortex (PFC), amygdala, and anterior cingulate cortex (ACC; Davidson, Putnam, \& Larson, 2000). Recent research specifically emphasized the 
role of distinct subdivisions of the PFC in emotional regulation. Several studies have found activation in the orbitofrontal cortex (OFC), dorsolateral PFC (dlPFC), dorsomedial PFC (dmPFC), ventromedial PFC (vmPFC), ventrolateral PFC (vlPFC), and ACC during the cognitive reappraisal of emotional stimuli (Beauregard, Lévesque, \& Bourgouin, 2001; Ochsner, Bunge, Gross, \& Gabrieli, 2002; Ochsner et al., 2004; Levesque et al., 2004; Phan et al., 2005; Urry et al., 2006; Banks, Eddy, Angstadt, Nathan, \& Phan, 2007). The recruitment of prefrontal regions has been suggested to be associated with a reduction in amygdala activation, a crucial structure for the generation and expression of emotions (Hariri, Bookheimer, \& Mazziotta, 2000; Schaefer et al., 2002; Hariri, Mattay, Tessitore, Fera, \& Weinberger, 2003; Phan et al., 2005; Urry et al., 2006; Juruena et al., 2010). Therefore, a proposition that explains the neural mechanism that underlies emotional regulation would involve a possible inhibitory PFCamygdala pathway (Davidson et al., 2000).

The involvement of multiple prefrontal areas during emotional regulation and its relationship with amygdala activity has raised the question of which specific subdivisions of the PFC are involved in the different forms of emotional regulation. Studies on cognitive reevaluation (reappraisal) observed a significant activation pattern in the PFC (dorsal and lateral regions) associated with a decrease in amygdala activation, thus suggesting that the former might modulate its activity through top-down inhibitory mechanisms (Beauregard et al., 2001; Ochsner et al., 2002; Levesque et al., 2003, 2004; Ochsner et al., 2004; Ochsner \& Gross, 2005; Phan et al., 2005; Ray et al., 2005; Ohira et al., 2006). Eippert et al. (2007) investigated the effect of PFC modulation of amygdala activity during the visualization of threat-related pictures. The authors used functional magnetic resonance imaging (fMRI) to investigate the brain structures activated when volunteers visualized threat-related images. The volunteers were instructed to regulate their emotions through strategies of cognitive reevaluation to increase or decrease their emotional responses. A decrease in negative affect during the visualization of threatening images was associated with activation of the anterior cingulate cortex, dlPFC, and left OFC. The same activation pattern was found bilaterally during the increase in negative affect. Both an increase and decrease in amygdala activity was observed during the use of emotional regulation strategies aimed at increasing and decreasing negative affect, respectively. This work demonstrated that the amygdala responses to threat-related stimuli can be modulated by cognitive strategies depending on the recruitment of prefrontal regions (Eippert et al., 2007). A similar study (Urry et al., 2006) supported this hypothesis. The relationship between responses of the PFC and amygdala during emotional regulation was specifically evaluated in an elderly population. During a cognitive reevaluation situation in which subjects voluntarily reduced the elicitation of negative emotion, an inverse correlation was found between vmPFC and amygdala activity, suggesting a possible inhibitory role played by the former.

Classic studies that used animals and humans (Morgan, Romanski, \& LeDoux, 1993; Sotres-Bayon, Cain, \& LeDoux, 2006; Schiller, Levy, Niv, LeDoux, \& Phelps, 2008; Delgado, Neaering, LeDoux, \& Phelps, 2008; Hartley \& Phelps, 2010) demonstrated that the PFC is fundamental for the extinction of conditioned fear. One study (Morgan \& LeDoux, 1999) investigated the neural basis of such extinction and showed that the mPFC plays a key role in the regulation of conditioned fear extinction in rats. Therefore, understanding how this mechanism was involved in anxiety disorders such as phobias, panic disorder, and PTSD in humans, was needed because these pathologies have been associated with the impaired extinction of aversive memories. In fact, recent studies reported that several forms of emotional regulation (e.g., extinction, cognitive regulation, and memory reconsolidation) depend on neural substrates related to a common pathway involved in the processing of aversive stimuli (Delgado et al., 2008; Hartley \& Phelps, 2010).

The model of amygdala inhibition by the PFC has been the focus of several studies to explain the neural correlates of certain psychiatric disorders such as depression (Drevets et al., 1992; Beauregard, Paquette, \& Levesque, 2006; Johnstone, van Reekum, Urry, Kalin, \& Davidson, 2007), anxiety (Lanius et al., 2004), social phobia (Birbaumer et al., 1998), and PTSD (Bryant et al., 2005). The increased amygdala activation observed in some psychiatric disorders is hypothesized to result from dysfunction of the inhibitory mechanism exerted by the PFC (Rauch et al., 2000). For example, an overactive amygdala may be associated with the symptoms of hyperarousal generally found in PTSD, including exaggerated startle responses, irritability, anger outbursts, and general hypervigilance (Weiss, 2007).

However, the question of which specific prefrontal connections regulate amygdala modulation remains unanswered. The dlPFC has few connections with the amygdala and is unlikely to directly influence the activity of this structure (McDonald, 1998). The dlPFC might influence amygdala activity by modulating posterior areas of perceptual processing (i.e., occipital/parietal cortex) to influence amygdala activation (Ochsner et al., 2002; Ochsner \& Gross, 2005). One possible alternative is that the dIPFC influences the amygdala through the OFC, which is situated at the junction between prefrontal and limbic areas, exhibiting dense connections with both the dlPFC and amygdala in primates (McDonald, 1998; Ghashghaei, Hilgetag, \& Barbas, 2007). Anatomically, the vmPFC in primates is densely connected with the amygdala (Barbas, 1995; Carmichael \& Price, 1995). 
Thus, the prefrontal region possibly related to inhibitory control over the amygdala may be the vmPFC (Price, 2005). A functional study showed an inverse correlation between the vmPFC and amygdala during a task of emotional regulation, thus strengthening the hypothesis that this PFC region plays a key role in affect regulation (Urry et al., 2006). The vmPFC has dense connections with the amygdala, facilitating bidirectional communication between these areas (Stefanacci \& Amaral, 2002). Data that support the assertion that the vmPFC exerts inhibitory control over the amygdala have shown it is critically involved in the pathogenesis of PTSD. The model proposes that amygdala activity plays a crucial role in the experience of negative affect, such as experiences of anxiety (Koenigs \& Grafman, 2009). In healthy brains, this activity is thought to be regulated via top-down inputs by the vmPFC, reducing the experience of negative affect. However, dysfunctional vmPFC activity may impair amygdala inhibition, resulting in a hyperactive amygdala and pathological distress, such as that seen in PTSD.

Thus, the present review assesses the validity of the PFC-amygdala circuit as a main neural correlate of the emotional regulation deficits observed in PTSD. A bibliographic search was performed in the Medline, LILACS, Scielo, ISI, and Cochrane databases using the terms "post-traumatic stress disorder (PTSD)," "prefrontal cortex," and "amygdala" for studies published between 1996 and 2010. We used 101 papers that were directly related to our theoretical proposition.

\section{Amygdala-prefrontal cortex model in the pathophysiology of posttraumatic stress disorder}

Posttraumatic stress disorder is an anxiety disorder that develops following exposure to a traumatic event. Events that precipitate PTSD include terrifying or lifethreatening situations such as sexual assault and natural disasters. The disorder is characterized by a reaction of intense fear, helplessness, or horror when the individual experiences, testifies about, or is faced with one or more events that involve death, severe wounds, or a threat to one's own or another's physical integrity. The symptoms include reexperiencing the traumatic event, avoidance of trauma-related situations, blunted affect (emotional numbness), and hyperarousal (American Psychiatric Association [APA], 1994).

Posttraumatic stress disorder is one psychiatric condition in which disruption of amygdala inhibition through prefrontal structures has been proposed to explain the pathophysiology of the disorder. Studies that investigated negative emotional processing in PTSD patients demonstrated hypoactivation of the mPFC but hyperactivation of the amygdala (Etkin \& Wager, 2007). Thus, the PFC-amygdala dysfunction model comprises two main elements: $(i)$ the emotional distress that characterizes PTSD arises from amygdala hyperactivity and (ii) amygdala hyperactivation is caused by defective inhibition from a hypoactive mPFC (Milad, Rauch, Pitman, \& Quirk, 2006; Rauch, Shin, \& Phelps, 2006).

The role of the amygdala in this model is supported by animal studies that emphasized its implication in memory consolidation. The amygdala modulates memory consolidation with the storage of emotionally relevant information and plays a critical role in fear and anxiety. For example, neuronal morphology and neurotransmitter content in the amygdala in rats exposed to a single prolonged stressor as an animal model for human PTSD has been investigated (Cui, Sakamoto, Higashi, \& Kawata, 2008). Changes in morphology (i.e., an increase in dendritic arborization of pyramidal neurons in the basolateral amygdala) induced by a single prolonged stressor were mediated through enhanced neuropeptide $\mathrm{Y}$ function. The authors suggested that this structural plasticity in the amygdala may provide a cellular and molecular basis of psychiatric disorders such as PTSD.

In neuroimaging and lesion studies in humans, mPFC-mediated inhibition of the amygdala has been suggested to be a neural mechanism involved in the extinction of fear conditioning. This is relevant because PTSD symptomatology has been linked to a defect in fear extinction processes (Milad et al., 2006; Rauch et al., 2006). Posttraumatic stress disorder can be seen as a failure in the trauma recovery process (Yehuda \& LeDoux, 2007). The disorder may also result from an enhanced association between a traumatic event (unconditioned stimulus) and the environment (conditioned stimulus), such as that seen in aversive conditioning (Charney \& Deutch, 1996; Pitman, 1989; Wessa \& Flor, 2007; Yehuda \& LeDoux, 2007). In fact, studies that used the aversive conditioning model in patients diagnosed with PTSD found an enhanced response, indexed by heart rate and skin conductance, during the phases of fear conditioning and extinction (Orr et al., 2000; Peri, BenShakhar, Orr, \& Shalev, 2000).

The neural correlates of fear conditioning and extinction processes in patients with PTSD were investigated by Bremner et al. (2005) using positron emission tomography. Women who were sexually abused during childhood and subsequently diagnosed with PTSD performed a task in which the conditioned and unconditioned stimuli were a blue square and electric shock, respectively. Compared with the control group (i.e., women with no history of sexual abuse), women with PTSD exhibited increased activation of the amygdala during the acquisition phase of conditioning, whereas during the extinction phase, a decrease was found in ACC activity (Bremner et al. 2005). Milad et al. (2009) investigated whether the extinction of fear responses is impaired in PTSD and whether such impairment is related to dysfunctional activation of brain regions known to be involved in fear extinction. In the PTSD group, greater 
amygdala activation was observed during extinction learning, with lesser activation of the vmPFC during extinction recall. Moreover, the magnitude of extinction across all subjects correlated with vmPFC activation during extinction recall testing, supporting the hypothesis that fear extinction is impaired in PTSD.

As described in the following sections, other studies have also observed changes in brain responses in PTSD patients using diverse trauma- and nontraumarelated stimuli.

\section{Brain processing of trauma-related stimuli assessed by script-driven imagery paradigms}

The advantage of using stimulation related to the trauma is the possibility of inducing and reproducing PTSD symptoms in the laboratory, which allows the processing of the traumatic event to be directly investigated. The best established paradigm for this approach is the "scriptdriven imagery" in which the participants are instructed to carefully listen to a script specifically related to their trauma and imagine the event as vividly as possible.

Based on this approach, Rauch et al. (1996) conducted a study on PTSD patients using positron emission tomography. Increased activation was found in the amygdala, rostral anterior cingulate cortex, and other paralimbic regions when participants listened to the traumatic script compared with the neutral script. Shin et al. (1999) used a similar methodology and found that patients with PTSD had increased activity in the orbitofrontal cortex compared with controls (i.e., participants with a history of trauma but not diagnosed with PTSD). Moreover, the PTSD group exhibited decreased activation of the ACC and prefrontal regions in general. Interestingly, decreased activity in the left inferior frontal gyrus was observed only in PTSD patients during exposure to the traumatic script, thus suggesting a change in prefrontal region function and supporting the model of PFC-amygdala dysfunction in PTSD.

The same group of researchers studied Vietnam veterans and army nurses with and without a diagnosis of PTSD (Shin et al., 2004a). In the PTSD group, decreased activity of the medial frontal gyrus was found during exposure to a traumatic script compared with a neutral script. An increase in amygdala activity was also observed exclusively in the group of veterans who suffered from PTSD. Notably, both veterans and nurses exhibited an inverse correlation between the activity levels of the medial frontal gyrus and amygdala. Additionally, symptom severity was found to positively and negatively correlate with amygdala and medial frontal gyrus activity, respectively. These findings strongly suggest that PTSD symptoms may be related to PFC-amygdala circuit dysfunction.

However, some evidence contradicts the PFCamygdala dysfunction model. Using the script-driven imagery paradigm, Gilboa et al. (2004) conducted an analysis of connectivity to investigate the pattern of brain activation in subjects with a history of work or motor vehicle accidents, half of whom were diagnosed with PTSD. This type of analysis allows one to observe the relationships between the activation patterns of different cerebral areas, which might indicate functional connectivity. Such analyses showed a positive relationship between amygdala activity and the activity of other structures, such as the ACC and sub-callous gyrus, in PTSD subjects. Because no expected pattern was observed, the proposed model of amygdala inhibitory circuits through prefrontal structures was not corroborated.

Some research has found peculiar results. Britton, Phan, Taylor, Figure, and Liberzon (2005) studied a sample of war veterans with and without PTSD and a group of subjects who never fought in wars (controls). In the comparison between traumatic/stressful and neutral scripts, the three groups exhibited deactivation in the mPFC but in different regions. Veterans with PTSD exhibited deactivation in the rostral ACC (rACC), whereas those without PTSD and controls exhibited deactivation in the vmPFC. With regard to the amygdala, the results were even more intriguing. No results were found for the amygdala in the group of veterans with PTSD, whereas those without PTSD (i.e., the resilient group) exhibited deactivation in this region (i.e., heightened response to the neutral script). The control group, in contrast, exhibited amygdala activation. Additionally, amygdala activity inversely correlated with the traumatic experience, which disagrees with the hypothesis of amygdala hyperactivity in PTSD symptomatology.

Two fMRI studies provided relevant evidence that favors the model of a dysfunctional PFC-amygdala circuit in PTSD. The first study showed a decrease in the activity of medial prefrontal regions in PTSD subjects compared with controls (i.e., traumatized subjects without a diagnosis of PTSD) when exposed to traumatic scripts (Lanius et al., 2001). The second study investigated whether nontraumatic autobiographic negative scripts produced the same pattern of brain activity (Lanius et al., 2003). An activation pattern similar to that observed for trauma-related script-driven imagery was found (i.e., decreased activation in the anterior cingulate gyrus in PTSD patients compared with controls). Lindauer et al. (2004) studied brain activation patterns in police officers with and without PTSD using single photon emission computed tomography. In the comparison between traumatic and neutral scripts, reduced activation in the medial frontal gyrus was observed in PTSD subjects compared with controls (i.e., police officers without PTSD), supporting the PFCamygdala dysfunction model. 


\section{Processing of trauma-related stimuli: other paradigms}

In addition to script-driven imagery, other paradigms have been used to investigate the neurobiology of PTSD. These paradigms include other trauma-related stimuli, such as words, sounds, images, and even smells, that lead to the traumatic experience.

Protopopescu et al. (2005) studied the processing of trauma-related words in individuals with PTSD using fMRI. The work investigated the time course of amygdala activation in response to negative words (general words and words related to the trauma). Initially, patients with PTSD had increased activity in the left amygdala only during the processing of trauma-related words. The response of the amygdala was found to positively correlate with the severity of PTSD symptoms. These finding also lend support to the hypothesis of PFC-amygdala circuit dysfunction in PTSD.

Shin et al. (1997) investigated the neural correlates of visualization and imagery of war-related pictures and negative and neutral pictures in war veterans with and without PTSD. The group of veterans with PTSD exhibited increased activity in the right amygdala and ventral anterior cingulate gyrus while producing mental images related to combat. Hendler et al. (2003) also investigated the processing of images related and unrelated to war in veterans with and without PTSD. The pictures were or were not presented subliminally. Interestingly, amygdala activation was greater in PTSD subjects than in controls, regardless of the picture content and level of consciousness at which the picture was presented, suggesting general amygdala hyperactivity in PTSD.

Morey, Petty, Cooper, Labar, and McCarthy (2008) conducted a study in which Iraqi and Afghanistan veterans were exposed to neutral and war pictures intercalated with a cognitive task. This task consisted of pushing a key for recognition of geometric shapes (circles and squares). During the visualization of trauma-related pictures, a positive correlation was found between the severity of PTSD symptoms and activation of the vmPFC, inferior frontal gyrus, and anterior cingulate gyrus. Such a finding was interpreted as a greater prefrontal involvement in an attempt to regulate affect. Additionally, a negative correlation was found between symptom severity and activation in cognitive-processing areas (i.e., medial frontal and dorsal anterior cingulate gyri) during the performance of the cognitive task, suggesting executive function impairment in PTSD patients. This finding also suggests different patterns of brain activation in PTSD depending on symptom severity and the type of processing system recruited.

Researchers have also employed sounds to investigate the neural circuits that underlie PTSD (Liberzon et al., 1999). Three groups of volunteers (veterans with PTSD, veterans without PTSD, and individuals who never fought in war) were exposed to war-related sounds (e.g., explosions, helicopters, shootouts) and neutral sounds. The results showed activation in the ACC and medial prefrontal gyrus in the three groups of subjects. However, increased activation in the left amygdala was noted only in veterans with PTSD. Thus, although no specific decrease in prefrontal activity had been identified, amygdala hyperactivity supported the model assessed in the present article.

In studies that used similar methodologies, Zubieta et al. (1999) reported hyperactivation of the mPFC in response to trauma-related sounds in war veterans with PTSD, providing contradictory evidence for the present model. Bremner et al. (1999) observed that exposure to sounds and images of war resulted in decreased activity in the mPFC in veterans with PTSD. Pissiota et al. (2002) noted that veterans with PTSD exhibited increased activity in the right amygdala and periaqueductal gray matter (PAG) in response to war-related sounds compared with controls (i.e., neutral sounds), supporting the validity of amygdala activity disruption.

Brain responses to olfactory cues have also been investigated in patients with PTSD. War veterans with and without PTSD were exposed to odors that might be related to their trauma (e.g., the smell of fuel), negative nontrauma-related odors (e.g., hydrogen sulfide), positive odors (e.g., vanilla), and neutral stimuli (e.g., odorless air). The study showed that veterans with PTSD reported that the fuel smell was the most negative and stressful odor compared with the control odors. The exposure to such an odor was related to increased activity in the amygdala, insula, and ACC. A decrease in lateral PFC activity was also observed (Vermetten, Schmahl, Southwick, \& Bremner, 2007).

Two studies that used trauma-related pictures (Yang, $\mathrm{Wu}, \mathrm{Hsu}, \& \mathrm{Ker}, 2004)$ and words (Bremner et al., 2003) reported hyperactivation of the ACC in patients with PTSD. However, other studies reported increased activation in this structure during the processing of trauma-related stimuli (Liberzon et al., 1999; Zubieta et al., 1999; Vermetten et al., 2007; Morey et al., 2008).

Despite these various findings, the main result was decreased activity in medial prefrontal areas (i.e., ACC) associated with increased activation of the amygdala during trauma-related stimulus processing. However, some studies also found increased activation in prefrontal structures including the ACC itself, thus leaving the issue open regarding which specific prefrontal region plays a key role in the model of PFCamygdala circuit dysfunction.

\section{Processing of nontrauma-related stimuli}

Another approach usually used in PTSD neuroimaging studies is nontrauma-related stimulation, in which emotional facial expressions are taken into 
account. This approach is based on the idea that PTSD may be generally linked to changes in the processing of emotional stimuli and not specifically to trauma-related stimuli. This view widens the possibility that PTSD involves not only fear conditioning, which has indeed been debated in the literature (Koenigs \& Grafman, 2009; Shin \& Handwerger, 2009).

With the aim of observing general fear processing in patients with PTSD, Williams et al. (2006) employed facial expressions as nontrauma-related stimuli. Groups of individuals with and without PTSD were instructed to pay attention to either neutral or fearful faces. Compared with the control group, the PTSD group showed a reduction in the activity of the $\mathrm{mPFC}$, particularly the right $\mathrm{ACC}$, during the visualization of fearful images. Nevertheless, no increase in amygdala activity was observed (Williams et al., 2006). In a similar work that used fearful, neutral, and happy faces, Shin et al. (2005) studied firemen and war veterans with and without PTSD. The group of PTSD subjects exhibited increased activity in the amygdala and decreased activity in the mPFC in response to fearful faces compared with happy faces. Additionally, a negative correlation was found between amygdala and mPFC activity, supporting the idea of failure in the regulation of amygdala activity in subjects with PTSD.

Although the pattern of prefrontal hyperactivity was previously described in facial expression paradigms (Shin et al., 2005; Williams et al., 2006), an earlier study (Rauch et al., 2000) reported no significant results for the PFC. These authors found only an increase in amygdala activity in response to negative faces compared with positive faces and a positive correlation between PTSD symptom severity and amygdala activity. The fact that emotional faces were presented for only $33 \mathrm{~ms}$ (i.e., without the subject's conscious awareness of their display) may have minimized the role of the $\mathrm{mPFC}$, justifying the absence of results regarding these high-order areas (Williams et al., 2006). However, another work that used masked faces in a shorter period of time $(16.7 \mathrm{~ms})$ found not only amygdala activation in response to fearful faces but also activation of the mPFC (Bryant et al., 2008).

Armony, Corbo, Clement, and Brunet (2005) examined the amygdala response to the visualization of happy and fearful facial expressions. The sample included individuals who had been recently traumatized and presented acute PTSD. In the condition in which faces were masked, a positive correlation was found between amygdala activity and PTSD severity during the visualization of fearful faces, suggesting that changes in the amygdala may already appear before the establishment of chronic PTSD itself.

The emotional Stroop test demonstrated decreased activity in the ACC in PTSD patients (Shin et al., 2001; Bremner et al., 2004), a finding that was not observed in the classic Stroop test (Stroop, 1935), which might indicate specific cingulate cortex dysfunction for emotional stimuli in PTSD (Bremner et al., 2004).
Under resting conditions, Chung et al. (2006) found increased activity in the amygdala and other limbic areas in addition to a decrease in the superior frontal gyrus in PTSD patients compared with controls (i.e., no trauma). These results appear to reflect a generalized failure in the ability to regulate emotions. Phan, Britton, Taylor, Figure, and Liberzon (2006), however, studied three groups of subjects (i.e., veterans with PTSD, veterans without PTSD, and nonveterans without PSTD) and found differences in the activation of amygdala and mPFC regions that do not fit the model of amygdala hyperactivity and $\mathrm{mPFC}$ hypofunction. The paradigm consisted of visualizing aversive, neutral, and blank pictures on the screen. Increased activity in the dorsal area of the mPFC was observed in the three groups in response to the negative images compared with the neutral images. Importantly, only the group of veterans without PTSD exhibited activation in the vmPFC, a possible pathway for amygdala downregulation. These findings indicate the need to identify more precisely the prefrontal regions involved in emotional regulation.

In summary, studies of nontrauma-related stimuli have also provided various results, with a predominant reduction in the activity of the $\mathrm{mPFC}$ and increased amygdala activation. Altogether, these results suggest that the general processing of emotions is altered in individuals with PTSD.

\section{Relationships of causality between the prefrontal-amygdala circuit and the development of PTSD}

The majority of imaging studies reveal the neural correlates of a given process but do not indicate causality. However, lesion studies, by principle, can elucidate the causal contribution of a brain region to a specific function. By definition, lesion studies can contribute to the elucidation of whether a causal relationship exists between the mPFC and amygdala in PTSD by determining the areas that influence the development of such a disorder. In the recent Vietnam Head Injury Study, researchers tested the main prediction of the mPFCamygdala model of PTSD pathogenesis (Koenigs et al., 2008). The predictions were that if PTSD symptomatology was caused by amygdala hyperactivity attributable to mPFC dysfunction, then veterans with amygdala damage would have a reduced likelihood of developing PTSD. Veterans with PFC damage but an intact amygdala would also have a greater probability of developing PTSD. They studied war veterans distributed in the following groups: (1) lesions of the $\operatorname{vmPFC}(n=40),(2)$ lesions of the amygdala $(n=15)$, (3) lesions that affected neither the vmPFC nor amygdala $(n=133)$, and (4) no brain lesions $(n=52)$. Almost half $(48 \%)$ of the veterans without brain lesions developed PTSD, which was similar to the prevalence $(40 \%)$ observed in veterans with lesions that 
involved neither the vmPFC nor amygdala. None of the veterans with focal lesions of the amygdala developed PTSD, thus suggesting that this structure plays a crucial role in the pathophysiology of the disorder. Nevertheless, in clear contrast to the predictions associated with the PFC-amygdala model, the prevalence of PTSD in the group of patients with lesions of the VmPFC was significantly lower (18\%). This decreased susceptibility to PTSD suggests that the mPFC-amygdala interaction is not uniformly inhibitory. The neurobiological basis of the mPFC-amygdala interaction depends on distinct excitation and inhibition circuits. Animal studies indicate that vmPFC inputs may have opposite effects, depending on the target nucleus and particular vmPFC subfield from which the input originates (Likthik, Pelletier, Paz, \& Paré, 2005; Quirk, Likhtik, Pelletier, \& Paré, 2003). Thus, further research will be necessary to elucidate the nature of the interaction between the vmPFC and amygdala and how dysfunction in this circuit contributes to the pathogenesis of PTSD.

Other studies indicated that the protection that results from lesions of the amygdala requires further investigation because previous reports showed that individuals who had half of their amygdala surgically removed developed PTSD (Adami, Konig, Vetter, Hausmann, \& Conca, 2006; Smith, Abou-Khalil, \& Zald, 2008). Adami et al. (2006) conducted a case study of a 19-year-old patient with a history of childhood abuse who presented PTSD symptoms 2 weeks after a surgery that resected the left amygdala because of severe epilepsy. Additionally, Smith et al. (2008) reported a case of a 48-year-old woman who presented severe epilepsy and had her left amygdala removed. Two years later, she developed PTSD after suffering a car accident. Therefore, the protective role of lesions of the amygdala in the development of PTSD should be interpreted with caution.

To determine the risk factors for developing PTSD, Shin and Handwerger (2009) recently studied monozygotic twins who differed in their exposure to the Vietnam War. Veterans with PTSD and their twin brothers who were not exposed to war exhibited higher rates of cerebral glucose metabolism in the dorsal anterior/ midcingulate cortices compared with those without PTSD and their respective twins. Critically, the activity of these areas in the non-exposed twin correlated with the severity of PTSD symptoms in twins exposed to such trauma. In fact, hyperactivity of the dorsal ACC (dACC) in PTSD related to emotional or conscious experience has been proposed (Etkin \& Wager, 2007). The rACC appears to be more directly linked to the PFC-amygdala dysfunction model once it is associated with the mechanisms of emotional regulation (Etkin \& Wager, 2007).

\section{Discussion}

Classic studies on fear conditioning and extinction in animals have provided a basis for a model of the brain circuits involved in anxiety disorders in humans, such as PTSD. The fundamental hypothesis is that PTSD is characterized by hyperactivity of the amygdala with concomitant failure in the top-down inhibitory control mediated by PFC regions. Notably, however, PTSD, despite the similarity, is not restricted to Pavlovian conditioning. PTSD is a condition with very characteristic symptoms of dissociation and revival, with not only an enhanced reaction to fear but also a variety of other emotions such as blame, shame, sadness, and anger (Koenigs \& Grafman, 2009; Shin \& Handwerger, 2009). Several human neuroimaging studies noted that the most common findings are actually hyperactivity of the amygdala and mainly a decrease in the activity of mPFC structures, although some studies point in other directions.

Koenigs and Grafman (2009) addressed the hypothesis of enhanced activation of the amygdala in PTSD in which responses to fear and anxiety were abolished after amygdala lesions. A first possibility is that amygdala damage abolishes the development of PTSD among combat veterans and supports the assertion that amygdala hyperactivity plays a causal role in the pathophysiology of PTSD. A second possibility is that emotional memory enhancement observed in PTSD relies on amygdala hyperactivity. A third possibility is that the role of the amygdala is related to the function of the detection and evaluation of environmental cues, which may signal threats. Such detection appears to be exaggerated in PTSD. Obviously, these hypotheses are not mutually exclusive. An extensive lesion of the amygdala can impede the development of PTSD by impairing the detection of threatening cues, impeding the expression of fear and anxiety and altering the formation of emotional memories.

The role of the medial prefrontal regions in PTSD, such as the anterior cingulate and ventromedial and orbitofrontal cortices, include various functions of complex and interconnected structures. The most common proposition is that a hypoactive mPFC would fail to regulate the responses of the amygdala, thus impairing fear extinction (Rauch et al., 2006) and the mechanisms of emotional regulation (Etkin \& Wager, 2007; Yehuda \& LeDoux, 2007). Koenigs and Grafman (2009) also suggested the hypothesis that a hypoactive mPFC can result from the chronic stress associated with PTSD or perhaps amygdala dysfunction. The authors suggested that the role of the $\mathrm{mPFC}$ in PTSD may extend beyond amygdala inhibition, possibly mediating the patients' subjective experience of trauma. A hypoactive mPFC could lessen the subjective response to the traumatic experience by decreasing emotional responses, such as blame and shame, and acting to protect against the trauma. However, some studies of PTSD found a hyperactive $\mathrm{mPFC}$, making the interpretation of the role of this structure in this disorder difficult. Different mPFC 
nuclei might be related to different functions involved in emotion generation and emotional regulation.

Britton et al. (2005) found dACC activation and ventral ACC deactivation, supporting the hypothesis that different subdivisions of the ACC play differential roles in PTSD. Etkin and Wager (2007) mentioned that the rACC might reflect resilience and emotional regulation mechanisms. Thus, hypoactivity of this structure would reflect a failure of emotional regulation. The dACC, in turn, would be related to emotional or conscious experience. Hypoactivation, therefore, could be related to symptoms of emotional numbness and dissociation, whereas hyperactivation could be related to increased negative subjective experience.

In conclusion, the diversity of findings may derive from the fact that PTSD is a syndrome with a considerable heterogeneity of symptoms between individual patients. Some authors suggested the existence of distinct PTSD subgroups with specific underlying pathophysiology. In fact, a dissociative subtype of PTSD has been proposed (Lanius et al., 2010) for the Diagnostic and Statistical Manual of Mental Disorders, 5th edition, a classification supported by clinical and neuroimaging evidence in which approximately $30 \%$ of PTSD patients presented a preponderance of dissociative/avoidance symptoms instead of hyperarousal/intrusive symptoms. Grouping patients with different peritraumatic responses may be another of the factors that impede the full knowledge of this disorder, rendering contradictory findings on the PFC. Individuals with different peritraumatic reactions may also have differences in their fear circuitry. Additionally, different paradigms can show not only opposite results but also different technical approaches. Some inconsistencies in the findings may be attributable to the use of different contrasts, for example. Another factor might be the small sample size used by several studies, leading to less accurate results and poor interpretations.

Charney (2003) stated that the inconsistencies observed in the results of studies on anxiety disorders highlight the importance of addressing the neurobiological heterogeneity within psychiatric diagnoses. This aim can be achieved through the application of genetic, neuroimaging, and neurochemical approaches that can refine anxiety disorder phenotypes and elucidate the genotypes associated with these disorders. The complex influence of factors that mediate risk and resilience in the development of PTSD and other stress-related psychopathology was discussed in a recent review (Jovanovic \& Ressler, 2010). Biological factors such as genotype and neurobiology appear to interact with environmental factors such as childhood background and trauma load, affecting the pattern of reactivity and recovery in the aftermath of trauma exposure.

Nonetheless, amygdala and prefrontal structures exhibit distinct patterns in PTSD, thus supporting the model of a dysfunctional circuit (see Table 1). Importantly, other structures are also frequently found to have altered activity in patients with PTSD, such as the hippocampus (Shin et al., 2004b; Rauch et al., 2006) and visual cortex (Hendler et al., 2003). Neuroimaging studies have unquestionably allowed us to deepen our knowledge of the structural and physiological changes observed in patients with PTSD. Nevertheless, further studies are needed to better understand the neural correlates of such a complex and diverse disorder.

Table 1. Summary of the main neuroimaging findings

\begin{tabular}{|c|c|c|c|c|c|}
\hline $\begin{array}{l}\text { Article/ } \\
\text { year }\end{array}$ & Technique & Paradigm & Sample & $\begin{array}{l}\text { Activation } \\
\text { PTSD Group }\end{array}$ & $\begin{array}{l}\text { Deactivation } \\
\text { PTSD Group }\end{array}$ \\
\hline $\begin{array}{l}\text { Shin et al., } \\
\text { 2004a }\end{array}$ & PET & $\begin{array}{l}\text { Script-driven } \\
\text { imagery }\end{array}$ & $\begin{array}{l}\text { Male combat } \\
\text { veterans and female } \\
\text { nurse veterans with } \\
\text { and without PTSD }\end{array}$ & $\begin{array}{l}\text { Left amygdala and } \\
\text { right amygdala/ } \\
\text { periamygdaloid } \\
\text { cortex }\end{array}$ & Medial frontal gyrus \\
\hline $\begin{array}{l}\text { Lanius et } \\
\text { al., } 2001\end{array}$ & fMRI & $\begin{array}{l}\text { Script-driven } \\
\text { imagery }\end{array}$ & $\begin{array}{l}\text { Traumatized subjects } \\
\text { with and without } \\
\text { PTSD }\end{array}$ & & $\begin{array}{l}\text { Anterior cingulate } \\
\text { gyrus and medial } \\
\text { frontal gyrus }\end{array}$ \\
\hline $\begin{array}{l}\text { Lanius et } \\
\text { al., } 2003\end{array}$ & fMRI & $\begin{array}{l}\text { Script-driven } \\
\text { imagery }\end{array}$ & $\begin{array}{l}\text { Traumatized subjects } \\
\text { with and without } \\
\text { PTSD }\end{array}$ & & $\begin{array}{l}\text { Anterior cingulate } \\
\text { gyrus }\end{array}$ \\
\hline $\begin{array}{l}\text { Shin et } \\
\text { al., } 1999\end{array}$ & PET & $\begin{array}{l}\text { Script-driven } \\
\text { imagery }\end{array}$ & $\begin{array}{l}\text { Women with a } \\
\text { history of childhood } \\
\text { sexual abuse with } \\
\text { and without PTSD }\end{array}$ & Orbitofrontal cortex & $\begin{array}{l}\text { Anterior frontal } \\
\text { regions and left } \\
\text { inferior frontal gyrus }\end{array}$ \\
\hline
\end{tabular}


Table 1. continued

\begin{tabular}{|c|c|c|c|c|c|}
\hline $\begin{array}{l}\text { Article/ } \\
\text { year }\end{array}$ & Technique & Paradigm & Sample & $\begin{array}{l}\text { Activation } \\
\text { PTSD Group }\end{array}$ & $\begin{array}{l}\text { Deactivation } \\
\text { PTSD Group }\end{array}$ \\
\hline $\begin{array}{l}\text { Britton et } \\
\text { al., } 2005\end{array}$ & PET & $\begin{array}{l}\text { Script-driven } \\
\text { imagery }\end{array}$ & $\begin{array}{l}\text { Combat veterans } \\
\text { with and without } \\
\text { PTSD; healthy, aged- } \\
\text { matched noncombat } \\
\text { control subjects }\end{array}$ & $\begin{array}{l}\text { Dorsal anterior } \\
\text { cingulate cortex }\end{array}$ & $\begin{array}{l}\text { Rostral anterior } \\
\text { cingulate cortex }\end{array}$ \\
\hline $\begin{array}{l}\text { Rauch et } \\
\text { al., } 1996\end{array}$ & PET & $\begin{array}{l}\text { Script-driven } \\
\text { imagery }\end{array}$ & PTSD patients & $\begin{array}{l}\text { Amygdala and } \\
\text { rostral anterior } \\
\text { cingulate cortex }\end{array}$ & Broca's area \\
\hline $\begin{array}{l}\text { Liberzon } \\
\text { et al., } \\
1999\end{array}$ & SPECT & $\begin{array}{l}\text { Exposure to white } \\
\text { noise and combat } \\
\text { sounds }\end{array}$ & $\begin{array}{l}\text { Vietnam veterans } \\
\text { with PTSD, combat } \\
\text { control subjects, } \\
\text { and normal control } \\
\text { subjects }\end{array}$ & $\begin{array}{l}\text { Anterior cingulate } \\
\text { cortex/middle } \\
\text { prefrontal gyrus } \\
\text { (three groups), left } \\
\text { amygdala (PTSD } \\
\text { patients only) }\end{array}$ & \\
\hline $\begin{array}{l}\text { Pissiota et } \\
\text { al., } 2002\end{array}$ & PET & $\begin{array}{l}\text { Exposure to combat } \\
\text { and neutral sounds }\end{array}$ & PTSD veterans & $\begin{array}{l}\text { Right amygdala and } \\
\text { periaqueductal gray }\end{array}$ & \\
\hline $\begin{array}{l}\text { Vermetten } \\
\text { et al., } \\
2007\end{array}$ & PET & $\begin{array}{l}\text { Exposure to combat- } \\
\text { related odors }\end{array}$ & $\begin{array}{l}\text { Combat veterans } \\
\text { with and without } \\
\text { PTSD }\end{array}$ & $\begin{array}{l}\text { Amygdala, insula, } \\
\text { medial prefrontal } \\
\text { cortex, and anterior } \\
\text { cingulate cortex }\end{array}$ & $\begin{array}{l}\text { Lateral prefrontal } \\
\text { cortex }\end{array}$ \\
\hline $\begin{array}{l}\text { Yang et } \\
\text { al., } 2004\end{array}$ & fMRI & $\begin{array}{l}\text { Exposure to } \\
\text { earthquake and } \\
\text { neutral pictures }\end{array}$ & $\begin{array}{l}\text { Taiwanese } \\
\text { adolescents with } \\
\text { traumatic experience } \\
\text { of earthquake with } \\
\text { and without PTSD }\end{array}$ & & $\begin{array}{l}\text { Anterior cingulate } \\
\text { cortex }\end{array}$ \\
\hline $\begin{array}{l}\text { Bremner } \\
\text { et al., } \\
1999\end{array}$ & PET & $\begin{array}{l}\text { Exposure to war } \\
\text { sounds and pictures }\end{array}$ & $\begin{array}{l}\text { Combat veterans } \\
\text { with and without } \\
\text { PTSD }\end{array}$ & & $\begin{array}{l}\text { Medial prefrontal } \\
\text { cortex }\end{array}$ \\
\hline $\begin{array}{l}\text { Zubieta et } \\
\text { al., } 1999\end{array}$ & SPECT & $\begin{array}{l}\text { Exposure to combat } \\
\text { sounds and white } \\
\text { noise }\end{array}$ & $\begin{array}{l}\text { Veterans with PTSD, } \\
\text { combat control } \\
\text { subjects, and normal } \\
\text { control subjects }\end{array}$ & $\begin{array}{l}\text { Medial prefrontal } \\
\text { cortex }\end{array}$ & \\
\hline $\begin{array}{l}\text { Proto- } \\
\text { popescu } \\
\text { et al., } \\
2005\end{array}$ & fMRI & $\begin{array}{l}\text { Exposure to } \\
\text { trauma-related and } \\
\text { nontrauma-related } \\
\text { emotional words }\end{array}$ & $\begin{array}{l}\text { Sexual/physical } \\
\text { abuse PTSD and } \\
\text { normal control } \\
\text { subjects }\end{array}$ & $\begin{array}{l}\text { Initial amygdala } \\
\text { response to trauma- } \\
\text { related negative but } \\
\text { not nontrauma-relat- } \\
\text { ed negative }\end{array}$ & \\
\hline $\begin{array}{l}\text { Hendler } \\
\text { et al., } \\
2003\end{array}$ & fMRI & $\begin{array}{l}\text { Backward-masked } \\
\text { images of combat } \\
\text { and noncombat } \\
\text { content, presented } \\
\text { at below, near, and } \\
\text { above recognition } \\
\text { thresholds }\end{array}$ & $\begin{array}{l}\text { Combat veterans } \\
\text { with and without } \\
\text { PTSD }\end{array}$ & $\begin{array}{l}\text { Amygdala regardless } \\
\text { of content and rec- } \\
\text { ognition threshold of } \\
\text { the images }\end{array}$ & \\
\hline $\begin{array}{l}\text { Shin et } \\
\text { al., } 1997\end{array}$ & PET & $\begin{array}{l}\text { Exposure and } \\
\text { visual imagery of } \\
\text { neutral, negative, } \\
\text { and combat-related } \\
\text { pictures }\end{array}$ & $\begin{array}{l}\text { Combat veterans } \\
\text { with and without } \\
\text { PTSD }\end{array}$ & $\begin{array}{l}\text { Ventral anterior } \\
\text { cingulate gyrus and } \\
\text { right amygdala when } \\
\text { generating mental } \\
\text { images of combat } \\
\text { pictures }\end{array}$ & $\begin{array}{l}\text { Broca's area when } \\
\text { viewing combat } \\
\text { pictures }\end{array}$ \\
\hline $\begin{array}{l}\text { Bremner } \\
\text { et al., } \\
2003\end{array}$ & PET & $\begin{array}{l}\text { Retrieval of neutral } \\
\text { and emotionally } \\
\text { valenced word pairs }\end{array}$ & $\begin{array}{l}\text { Women with early } \\
\text { childhood sexual } \\
\text { abuse-related PTSD } \\
\text { and women without } \\
\text { abuse or PTSD }\end{array}$ & $\begin{array}{l}\text { Posterior cingulate, } \\
\text { left middle frontal } \\
\text { gyrus }\end{array}$ & $\begin{array}{l}\text { Orbitofrontal cortex, } \\
\text { anterior cingulate } \\
\text { cortex, and medial } \\
\text { prefrontal cortex }\end{array}$ \\
\hline
\end{tabular}


Table 1. continued

\begin{tabular}{|c|c|c|c|c|c|}
\hline $\begin{array}{l}\text { Article/ } \\
\text { year }\end{array}$ & Technique & Paradigm & Sample & $\begin{array}{l}\text { Activation } \\
\text { PTSD Group }\end{array}$ & $\begin{array}{l}\text { Deactivation } \\
\text { PTSD Group }\end{array}$ \\
\hline $\begin{array}{l}\text { Milad et } \\
\text { al., } 2009\end{array}$ & fMRI & $\begin{array}{l}\text { 2-day fear } \\
\text { conditioning and } \\
\text { extinction protocol }\end{array}$ & $\begin{array}{l}\text { Individuals diagnosed } \\
\text { with PTSD and } \\
\text { trauma-exposed non- } \\
\text { PTSD control subjects }\end{array}$ & $\begin{array}{l}\text { Amygdala (day } 1 \\
\text { extinction learning); } \\
\text { dACC (day } 2 \text { ex- } \\
\text { tinction recall) }\end{array}$ & $\begin{array}{l}\text { Ventromedial } \\
\text { prefrontal cortex } \\
\text { (day } 2 \text { extinction } \\
\text { recall) }\end{array}$ \\
\hline $\begin{array}{l}\text { Bremner } \\
\text { et al., } \\
2005\end{array}$ & PET & Conditioned fear & $\begin{array}{l}\text { Women with early } \\
\text { childhood sexual } \\
\text { abuse-related PTSD } \\
\text { and women without } \\
\text { abuse or PTSD }\end{array}$ & $\begin{array}{l}\text { Left amygdala (fear } \\
\text { acquisition) }\end{array}$ & $\begin{array}{l}\text { Anterior cingulate } \\
\text { cortex (fear } \\
\text { extinction) }\end{array}$ \\
\hline $\begin{array}{l}\text { Shin et } \\
\text { al., } 2001\end{array}$ & fMRI & $\begin{array}{l}\text { Emotional Counting } \\
\text { Stroop }\end{array}$ & $\begin{array}{l}\text { Combat veterans with } \\
\text { and without PTSD }\end{array}$ & & $\begin{array}{l}\text { Rostral anterior } \\
\text { cingulate cortex }\end{array}$ \\
\hline $\begin{array}{l}\text { Bremner } \\
\text { et al., } \\
2004\end{array}$ & PET & $\begin{array}{l}\text { Control, color } \\
\text { Stroop, and emo- } \\
\text { tional Stroop }\end{array}$ & $\begin{array}{l}\text { Women with early } \\
\text { childhood sexual } \\
\text { abuse-related PTSD } \\
\text { and women with } \\
\text { abuse but without } \\
\text { PTSD }\end{array}$ & & $\begin{array}{l}\text { Anterior cingulate } \\
\text { cortex (Emotional } \\
\text { Stroop) }\end{array}$ \\
\hline $\begin{array}{l}\text { Williams } \\
\text { et al., } \\
2006\end{array}$ & fMRI & $\begin{array}{l}\text { Unmasked fearful } \\
\text { faces }(500 \mathrm{~ms})\end{array}$ & $\begin{array}{l}\text { Subjects with } \\
\text { PTSD and matched } \\
\text { nontraumatized } \\
\text { healthy subjects }\end{array}$ & $\begin{array}{l}\text { Left amygdala (late } \\
\text { phase) }\end{array}$ & $\begin{array}{l}\text { Medial prefrontal } \\
\text { cortex activity (in } \\
\text { particular, right } \\
\text { anterior cingulate } \\
\text { cortex); right } \\
\text { amygdala (early } \\
\text { phase) }\end{array}$ \\
\hline $\begin{array}{l}\text { Shin et } \\
\text { al., } 2005\end{array}$ & fMRI & $\begin{array}{l}\text { Unmasked emotional } \\
\text { faces }(200 \mathrm{~ms})\end{array}$ & $\begin{array}{l}\text { Men with PTSD and } \\
\text { trauma-exposed men } \\
\text { without PTSD }\end{array}$ & $\begin{array}{l}\text { Amygdala (fearful } \\
\text { vs. happy faces) }\end{array}$ & $\begin{array}{l}\text { Medial prefrontal } \\
\text { cortex (fearful vs. } \\
\text { happy faces) }\end{array}$ \\
\hline $\begin{array}{l}\text { Rauch et } \\
\text { al., } 2000\end{array}$ & fMRI & $\begin{array}{l}\text { Masked emotional } \\
\text { faces ( } 33 \mathrm{~ms}) \text { by } \\
\text { neutral faces }\end{array}$ & $\begin{array}{l}\text { Combat veterans with } \\
\text { and without PTSD }\end{array}$ & $\begin{array}{l}\text { Amygdala (fearful } \\
\text { vs. happy faces) }\end{array}$ & \\
\hline $\begin{array}{l}\text { Bryant et } \\
\text { al., } 2008\end{array}$ & fMRI & $\begin{array}{l}\text { Masked emotional } \\
\text { faces }(16.7 \mathrm{~ms}) \text { by } \\
\text { neutral faces }\end{array}$ & $\begin{array}{l}\text { Subjects with } \\
\text { PTSD and matched } \\
\text { nontraumatized } \\
\text { healthy subjects }\end{array}$ & $\begin{array}{l}\text { Amygdala and } \\
\text { medial prefrontal } \\
\text { cortex (fearful } v s . \\
\text { neutral faces) }\end{array}$ & \\
\hline $\begin{array}{l}\text { Phan et } \\
\text { al., } 2006\end{array}$ & PET & IAPS* pictures & $\begin{array}{l}\text { Combat veterans with } \\
\text { and without PTSD } \\
\text { and gender-matched } \\
\text { healthy controls }\end{array}$ & $\begin{array}{l}\text { dorsomedial pre- } \\
\text { frontal cortex and } \\
\text { left amygdala }\end{array}$ & \\
\hline $\begin{array}{l}\text { Armony } \\
\text { et al., } \\
2005\end{array}$ & fMRI & $\begin{array}{l}\text { Fearful or happy } \\
\text { faces, presented } \\
\text { above or below } \\
\text { consciousness with } \\
\text { backward masking }\end{array}$ & $\begin{array}{l}\text { Individuals with acute } \\
\text { PTSD }\end{array}$ & Amygdala & \\
\hline $\begin{array}{l}\text { Chung et } \\
\text { al., } 2006\end{array}$ & SPECT & Resting condition & $\begin{array}{l}\text { PTSD patients and } \\
\text { age-matched healthy } \\
\text { subjects }\end{array}$ & Limbic regions & $\begin{array}{l}\text { Superior frontal } \\
\text { gyrus }\end{array}$ \\
\hline
\end{tabular}

*IAPS, International Affective Picture System (Lang, Bradley, \& Cuthbert, 1999). 


\section{References}

Adami, P., Konig, P., Vetter, Z., Hausmann, A., \& Conca, A. (2006) Post-traumatic stress disorder and amygdala-hippocampectomy. Acta Psychiatrica Scandinavica, 113, 360-363, discussion 363-364.

American Psychiatric Association (1994). Diagnostic and statistical manual of mental disorders. $4^{\text {th }}$ edition. Washington, D.C.: American Psychiatric Press.

Armony, J.L., Corbo, V., Clement, M.H., \& Brunet, A. (2005) Amygdala response in patients with acute PTSD to masked and unmasked emotional facial expressions. American Journal of Psychiatry, 162, 1961-1963.

Banks, S.J., Eddy, K.T., Angstadt, M., Nathan, P.J., \& Phan, K.L. (2007). Amygdala-frontal connectivity during emotion regulation. Social Cognitive and Affective Neuroscience, 2, 303-312.

Barbas, H. (1995). Anatomic basis of cognitive-emotional interactions in the primate prefrontal cortex. Neuroscience and Biobehavioral Reviews, 19, 499-510.

Beauregard, M., Lévesque, J., \& Bourgouin, P. (2001). Neural correlates of conscious self-regulation of emotion. Journal of Neuroscience, 21, RC165.

Beauregard, M., Paquette, V., \& Levesque, J. (2006). Dysfunction in the neural circuitry of emotional self-regulation in major depressive disorder. Neuroreport, 17, 843-846.

Birbaumer, N., Grodd, W., Diedrich, O., Klose, U., Erb, M., Lotze, M., ... Flor, H. (1998). fMRI reveals amygdala activation to human faces in social phobics. Neuroreport, 9, 1223-1226.

Bremner, J.D., Staib, L.H., Kaloupek, D., Southwick, S.M., Soufer, R., \& Charney, D.S. (1999). Neural correlates of exposure to traumatic pictures and sound in Vietnam combat veterans with and without posttraumatic stress disorder: a positron emission tomography study. Biological Psychiatry, 45, 806-816.

Bremner, J.D., Vythilingam, M., Vermetten, E., Southwick, S.M., Mcglashan, T., Staib, L.H., Soufer, R., \& Charney, D.S. (2003) Neural correlates of declarative memory for emotionally valenced words in women with posttraumatic stress disorder related to early childhood sexual abuse. Biological Psychiatry, 53, 879-889.

Bremner, J.D., Vermetten, E., Vythilingam, M., Afzal, N., Schmahl, C., Elzinga, B., \& Charney, D.S. (2004). Neural correlates of the classic color and emotional Stroop in women with abuse-related posttraumatic stress disorder. Biological Psychiatry, 55, 612-620.

Bremner, J.D, Vermetten, E., Schmahl, C., Vaccarino, V., Vythilingam, M., Afzal, N., Grillon, C., \& Charney, D.S. (2005). Positron emission tomographic imaging of neural correlates of a fear acquisition and extinction paradigm in women with childhood sexual-abuse-related post-traumatic stress disorder. Psychological Medicine, 35, 791-806.

Britton, J.C., Phan, K.L., Taylor, S.F., Figure, L.M., \& Liberzon, I (2005). Corticolimbic blood flow in posttraumatic stress disorder during script-driven imagery. Biological Psychiatry, 57, 832-840.

Bryant, R.A., Felmingham, K.L., Kemp, A.H., Barton, M., Peduto, A.S., Rennie, C., Gordon, E., \& Williams, L.M. (2005). Neura networks of information processing in posttraumatic stress disorder: a functional magnetic resonance imaging study. Biological Psychiatry, 58, 111-118.

Bryant, R.A., Kemp, A.H., Felmingham, K.L., Liddell, B., Olivieri, G., Peduto, A., Gordon, E., \& Williams, L.M. (2008). Enhanced amygdala and medial prefrontal activation during nonconscious processing of fear in posttraumatic stress disorder: an fMRI study. Human Brain Mapping, 29, 517-523.

Campbell-Sills, L., Barlow, D.H., Brown, T.A., \& Hofmann, S.G. (2006). Effects of suppression and acceptance on emotional responses of individuals with anxiety and mood disorders. Behavior Research and Therapy, 44, 1251-1263.

Carmichael, S.T., \& Price, J.L. (1995). Limbic connections of the orbital and medial prefrontal cortex in macaque monkeys. Journal of Comparative Neurology, 363, 615-641.

Charney, D.S. (2003). Neuroanatomical circuits modulating fear and anxiety behaviors. Acta Psychiatrica Scandinavica Supplementum, 417, 38-50.

Charney, D.S., \& Deutch, A. (1996). A functional neuroanatomy of anxiety and fear: implications for the pathophysiology and treatment of anxiety disorders. Critical Reviews in Neurobiology, 10, 419-446.

Chung, Y.A., Kim, S.H., Chung, S.K., Chae, J.H., Yang, D.W., Sohn, H.S., \& Jeong, J. (2006). Alterations in cerebral perfusion in posttraumatic stress disorder patients without re-exposure to accident-related stimuli. Clinical Neurophysiology, 117, 637-642.

Cui, H., Sakamoto, H., Higashi, S., \& Kawata, M. (2008). Effects of single-prolonged stress on neurons and their afferent inputs in the amygdala. Neuroscience, 152, 703-712.

Davidson, R.J., Putnam, K.M., \& Larson, C.L. (2000). Dysfunction in the neural circuitry of emotion regulation: a possible prelude to violence. Science, 289, 591-594.

Delgado, M.R., Nearing, K.I., Ledoux, J.E., \& Phelps, E.A. (2008). Neural circuitry underlying the regulation of conditioned fear and its relation to extinction. Neuron, 59, 829-838.

Drevets, W.C., Videen, T.O., Price, J.L., Preskorn, S.H., Carmichael, S.T., \& Raichle, M.E. (1992). A functional anatomical study of unipolar depression. Journal of Neuroscience, 12, 3628-3641.

Eippert, F., Veit, R., Weiskopf, N., Erb, M., Birbaumer, N., \& Anders, S. (2007). Regulation of emotional responses elicited by threatrelated stimuli. Human Brain Mapping, 28, 409-423.

Etkin, A., \& Wager, T.D. (2007). Functional neuroimaging of anxiety: a meta-analysis of emotional processing in PTSD, social anxiety disorder, and specific phobia. American Journal of Psychiatry, 164, 1476-1488.

Ghashghaei, H.T., Hilgetag, C.C., \& Barbas, H. (2007). Sequence of information processing for emotions based on the anatomic dialogue between prefrontal cortex and amygdala. Neuroimage, 34, 905-923

Gilboa, A., Shalev, A.Y., Laor, L., Lester, H., Louzoun, Y., Chisin, R., \& Bonne, O. (2004). Functional connectivity of the prefrontal cortex and the amygdala in posttraumatic stress disorder. Biological Psychiatry, 55, 263-272.

Gillath, O., Bunge, S.A., Shaver, P.R., Wendelken, C., \& Mikulincer, M. (2005). Attachment-style differences in the ability to suppress negative thoughts: exploring the neural correlates. Neuroimage, 28, 835-847.

Gross, J.J. (1998). Antecedent- and response-focused emotion regulation: divergent consequences for experience, expression, and physiology. Journal of Personality and Social Psychology, 74, 224-237.

Gross, J.J. (2002). Emotion regulation: affective, cognitive, and social consequences. Psychophysiology, 39, 281-291.

Hariri, A.R., Bookheimer, S.Y., \& Mazziotta, J.C. (2000). Modulating emotional responses: effects of a neocortical network on the limbic system. Neuroreport, 11, 43-48.

Hariri, A.R., Mattay, V.S., Tessitore, A., Fera, F., \& Weinberger, D.R. (2003). Neocortical modulation of the amygdala response to fearful stimuli. Biological Psychiatry, 53, 494-501.

Hartley, C.A., \& Phelps, E.A. (2010). Changing fear: the neurocircuitry of emotion regulation. Neuropsychopharmacology, 35, 136-146.

Hendler, T., Rotshtein, P., Yeshurun, Y., Weizmann, T., Kahn, I., BenBashat D, Malach, R., \& Bleich, A. (2003). Sensing the invisible: differential sensitivity of visual cortex and amygdala to traumatic context. Neuroimage, 19, 587-600.

Jackson, D.C., Mueller, C.J., Dolski, I., Dalton, K.M., Nitschke, J.B., Urry, H.L., ...Davidson, R.J. (2003). Now you feel it, now you don't: frontal brain electrical asymmetry and individual differences in emotion regulation. Psychological Science, 14, 612-617.

Johnstone, T., van Reekum, C.M., Urry, H.L., Kalin, N.H., \& Davidson, R.J. (2007). Failure to regulate: counterproductive recruitment of top-down prefrontal-subcortical circuitry in major depression. Journal of Neuroscience, 27, 8877-8884.

Jovanovic T., \& Ressler K.J. (2010). How the neurocircuitry and genetics of fear inhibition may inform our understanding of PTSD. American Journal of Psychiatry, 167, 648-662.

Juruena, M.F., Giampietro, V.P., Smith, S.D., Surguladze, S.A., Dalton, J.A., Benson, P.J., Cleare, A.J., \& Fu, C.H.Y. (2010) Amygdala activation to masked happy facial expressions. Journal of the International Neuropsychological Society, 16, 383-387.

Koenigs, M., \& Grafman, J. (2009). Posttraumatic stress disorder: the role of medial prefrontal cortex and amygdala. Neuroscientist, 15, 540-548.

Koenigs, M., Huey, E.D., Raymont, V., Cheon, B., Solomon, J., Wassermann, E.M., \& Grafman, J. (2008). Focal brain damage protects against post-traumatic stress disorder in combat veterans. Nature Neuroscience, 11, 232-237.

Lang, P.J., Bradley, M.M., \& Cuthbert, B.N. (1999). International affective picture system (IAPS): instruction manual and affective ratings. Bethesda, MD: NIMH Center for the Study of Emotion and Attention.

Lanius, R.A., Williamson, P.C., Densmore, M., Boksman, K., Gupta, M.A., Neufeld, R.W., Gati, J.S., \& Menon, R.S. (2001). Neura 
correlates of traumatic memories in posttraumatic stress disorder: a functional MRI investigation. American Journal of Psychiatry, 158, 1920-1922.

Lanius, R.A., Williamson, P.C., Hopper, J., Densmore, M., Boksman, K., Gupta, M.A., Neufeld, R.W., Gati, J.S., \& Menon, R.S. (2003) Recall of emotional states in posttraumatic stress disorder: an fMR investigation. Biological Psychiatry, 53, 204-210.

Lanius, R.A., Williamson, P.C., Densmore, M., Boksman, K., Neufeld, R.W., Gati, J.S., \& Menon, R.S. (2004). The nature of traumatic memories: a 4-T fMRI functional connectivity analysis. American Journal of Psychiatry, 161, 36-44.

Lanius, R.A., Vermetten, E., Loewenstein, R.J., Brand, B., Schmal, C., Bremner, D.J., \& Spiegel, D. (2010). A dissociative subtype of PTSD: clinical and neurobiological evidence for a dissociative subtype. American Journal of Psychiatry, 167, 640-647.

Levesque, J., Eugene, F., Joanette, Y., Paquette, V., Mensour, B., Beaudoin, G.,... Beauregard, M. (2003). Neural circuitry underlying voluntary suppression of sadness. Biological Psychiatry, 53, 502-510.

Levesque, J., Joanette, Y., Mensour, B., Beaudoin, G., Leroux, J.M., Bourgouin. P., \& Beauregard, M. (2004). Neural basis of emotional self-regulation in childhood. Neuroscience, 129, 361-369.

Liberzon, I., Taylor, S.F., Amdur, R., Jung, T.D., Chamberlain, K.R., Minoshima, S., Koeppe, R.A, \& Figure, L.M. (1999). Brain activation in PTSD in response to trauma-related stimuli. Biological Psychiatry, 45, 817-826.

Likhtik, E., Pelletier, J.G., Paz, R., \& Paré, D. (2005). Prefronta control of the amygdala. Journal of Neuroscience, 25, 7429-7437.

Lindauer, R.J., Booij, J., Habraken, J.B., Uylings, H.B., Olff, M., Carlier, I.V., ...Gersons, B.P.R. (2004). Cerebral blood flow changes during script-driven imagery in police officers with posttraumatic stress disorder. Biological Psychiatry, 56, 853- 861.

Lopes, P.N., Salovey, P., Cote, S., \& Beers, M. (2005). Emotion regulation abilities and the quality of social interaction. Emotion, $5,113-118$.

Mauss, I.B., Evers, C., Wilhelm, F.H., Gross, J.J. (2006). How to bite your tongue without blowing your top: implicit evaluation of emotion regulation predicts affective responding to anger provocation Personality and Social Psychology Bulletin, 32, 589-602.

Mauss, I.B., Wilhelm, F.H., \& Gross, J.J. (2003). Autonomic recovery and habituation in social anxiety. Psychophysiology, 40, 648-653.

McDonald, A.J. (1998). Cortical pathways to the mammalian amygdala. Progress in Neurobiology, 55, 257-332.

Milad, M.R., Rauch, S.L., Pitman, R.K., \& Quirk, G.J. (2006). Fear extinction in rats: implications for human brain imaging and anxiety disorders. Biological Psychology, 73, 61-71.

Milad, M.R., Pitman, R.K., Ellis, C.B., Gold, A.L., Shin, L.M., Lasko, N.B., ...Rauch, S.L. (2009). Neurobiological basis of failure to recall extinction memory in posttraumatic stress disorder. Biological Psychiatry, 66, 1075-1082.

Mocaiber, I., Pereira, M.G., Erthal, F.S., Figueira, I., MachadoPinheiro, W., Cagy, M., Volchan, E., \& Oliveira, L. (2009). Regulation of negative emotions in high trait anxious individuals: an ERP study. Psychology and Neuroscience, 2, 211-217.

Mocaiber, I., Pereira, M.G., Erthal, F.S., Machado-Pinheiro, W., David, I.A., Cagy, M., Volchan, E., \& de Oliveira, L. (2010). Fact or fiction? An event-related potential study of implicit emotion regulation. Neuroscience Letters, 476, 84-88.

Morey, R.A., Petty, C.M., Cooper, D.A., Labar, K.S., \& McCarthy, G. (2008). Neural systems for executive and emotional processing are modulated by symptoms of posttraumatic stress disorder in Irac War veterans. Psychiatry Research, 162, 59-72.

Morgan, M.A., Romanski, L.M., \& LeDoux, J.E. (1993). Extinction of emotional learning: contribution of medial prefrontal cortex. Neuroscience Letters, 163, 109-113.

Morgan, M.A., \& LeDoux, J.E. (1999). Contribution of ventrolateral prefrontal cortex to the acquisition and extinction of conditioned fear in rats. Neurobiology of Learning and Memory, 72, 244-251.

Ochsner, K.N., Bunge, S.A., Gross, J.J., \& Gabrieli, J.D. (2002) Rethinking feelings: an fMRI study of the cognitive regulation of emotion. Journal of Cognitive Neuroscience, 14, 1215-1229.

Ochsner, K.N., Ray, R.D., Cooper, J.C., Robertson, E.R., Chopra, S., Gabrieli, J.D., \& Gross, J.J. (2004). For better or for worse: neural systems supporting the cognitive down- and up-regulation of negative emotion. Neuroimage, 23, 483-499.

Ochsner, K.N., \& Gross, J.J. (2005). The cognitive control of emotion. Trends in Cognitive Sciences, 9, 242-249.
Ohira, H., Nomura, M., Ichikawa, N., Isowa, T., Iidaka, T., Sato, A., Fukuyama, S., Nakajima, T., \& Yamada, J. (2006). Association of neural and physiological responses during voluntary emotion suppression. Neuroimage, 29, 721-733.

Oliveira, L.A., Oliveira, L., Joffily, M., Pereira-Junior, P.P., Lang, P.J., Pereira, M.G., Figueira, I., \& Volchan, E. (2009). Autonomic reactions to mutilation pictures: positive affect facilitates safety signal processing. Psychophysiology, 46, 870-873.

Orr, S.P., Metzger, L.J., Lasko, N.B., Macklin, M.L., Peri, T., \& Pitman, R.K. (2000). De novo conditioning in trauma-exposed individuals with and without posttraumatic stress disorder. Journal of Abnormal Psychology, 109, 290-298.

Peri, T., Ben-Shakhar, G., Orr, S.P., \& Shalev, A.Y. (2000) Psychophysiologic assessment of aversive conditioning in posttraumatic stress disorder. Biological Psychiatry, 47, 512-519.

Phan, K.L., Fitzgerald, D.A., Nathan, P.J., Moore, G.J., Uhde, T.W., \& Tancer, M.E. (2005). Neural substrates for voluntary suppression of negative affect: a functional magnetic resonance imaging study. Biological Psychiatry, 57, 210-219.

Phan, K.L., Britton, J.C., Taylor, S.F., Figure, L.M., \& Liberzon, I. (2006). Corticolimbic blood flow during nontraumatic emotional processing in posttraumatic stress disorder. Archives of General Psychiatry, 63, 184-192.

Pissiota, A., Frans, O., Fernandez, M., Von Knorring, L., Fischer, H., \& Fredrikson, M. (2002). Neurofunctional correlates of posttraumatic stress disorder: a PET symptom provocation study. European Archives of Psychiatry and Clinical Neuroscience, 252, 68-75.

Pitman, R.K. (1989). Post-traumatic stress disorder, hormones, and memory. Biological Psychiatry, 26, 221-223.

Price, J.L. (2005). Free will versus survival: brain systems that underlie intrinsic constraints on behavior. Journal of Comparative Neurology, 493, 132-139.

Protopopescu, X., Pan, H., Tuescher, O., Cloitre, M., Goldstein, M., Engelien, W., ...Stern, E. (2005). Differential time courses and specificity of amygdala activity in posttraumatic stress disorder subjects and normal control subjects. Biological Psychiatry, 57, 464-473.

Quirk, G.J., Likhtik, E., Pelletier, J.G., \& Paré, D. (2003). Stimulation of medial prefrontal cortex decreases the responsiveness of central amygdala output neurons. Journal of Neuroscience, 23, 8800-8807.

Rauch, S.L., van der Kolk, B.A., Fisler, R.E., Alpert, N.M, Orr, S.P., Savage, C.R., ... Pitman, R.K. (1996). A symptom provocation study of posttraumatic stress disorder using positron emission tomography and script-driven imagery. Archives of General Psychiatry, 53, 380-387.

Rauch, S.L., Whalen, P.J., Shin, L.M., McInerney, S., Macklin, M.L., Lasko, N.B., Orr, S.P., \& Pitman, R.K. (2000). Exaggerated amygdala responses to masked facial stimuli in posttraumatic stress disorder: a functional MRI study. Biological Psychiatry, 47 , 769-776.

Rauch, S.L., Shin, L.M., \& Phelps, E.A. (2006). Neurocircuitry models of posttraumatic stress disorder and extinction: human neuroimaging research-past, present, and future. Biological Psychiatry, 60, 376-382.

Ray, R.D., Ochsner, K.N., Cooper, J.C., Robertson, E.R., Gabrieli, J.D., \& Gross, J.J. (2005). Individual differences in trait rumination and the neural systems supporting cognitive reappraisal. Cognitive, Affective and Behavioral Neuroscience, 5, 156-168.

Schaefer, S.M., Jackson, D.C., Davidson, R.J., Aguirre, G.K., Kimberg, D.Y., Thompson-Schill, S.L. (2002). Modulation of amygdalar activity by the conscious regulation of negative emotion. Journal of Cognitive Neuroscience, 14, 913-921.

Schiller, D., Levy, I., Niv, Y., LeDoux, J.E., \& Phelps, E.A. (2008). From fear to safety and back: reversal of fear in the human brain. Journal of Neuroscience, 28, 11517-11525.

Shin, L.M., Kosslyn, S.M., McNally, R.J., Alpert, N.M., Thompson, W.L., Rauch, S.L., Macklin, M.L., \& Pitman, R.K. (1997). Visual imagery and perception in posttraumatic stress disorder: a positron emission tomographic investigation. Archives of General Psychiatry, 54, 233-241.

Shin, L.M., McNally, R.J., Kosslyn, S.M., Thompson, W.L., Rauch, S.L., Alpert, N.M., ... Pitman, R.K. (1999). Regional cerebral blood flow during script-driven imagery in childhood sexual abuse-related PTSD: a PET investigation. American Journal of Psychiatry, 156, 575-584

Shin, L.M., Whalen, P.J., Pitman, R.K., Bush, G., Macklin, M.L., Lasko, N.B., ...Rauch, S.L. (2001). An fMRI study of anterior 
cingulate function in posttraumatic stress disorder. Biological Psychiatry, 50, 932-942.

Shin, L.M., Orr, S.P., Carson, M.A., Rauch, S.L., Macklin, M.L., Lasko, N.B., ... \& Pitman, R.K. (2004a). Regional cerebral blood flow in amygdala and medial prefrontal cortex during traumatic imagery in male and female Vietnam veterans with PTSD. Archives of General Psychiatry, 61, 168-176.

Shin, L.M., Shin, P.S., Heckers, S., Krangel, T.S., Macklin, M.L., Orr, S.P., Lasko, N., ... Rauch, S.L. (2004b). Hippocampal function in posttraumatic stress disorder. Hippocampus, 14, 292-300.

Shin, L.M., Wright, C.I., Cannistraro, P.A., Wedig, M.M., McMullin, K., Martis, B., ... Rauch, S.L. (2005). A functional magnetic resonance imaging study of amygdala and medial prefrontal cortex responses to overtly presented fearful faces in posttraumatic stress disorder. Archives of General Psychiatry, 62, 273-281.

Shin, L.M., \& Handwerger, K. (2009). Is posttraumatic stress disorder a stress-induced fear circuitry disorder? Journal of Traumatic Stress, 22, 409-415.

Smith, S.D., Abou-Khalil, B., \& Zald, D.H. (2008). Posttraumatic stress disorder in a patient with no left amygdala. Journal of Abnormal Psychology, 117, 479-484.

Sotres-Bayon, F., Cain, C.K., \& LeDoux, J.E. (2006). Brain mechanisms of fear extinction: historical perspectives on the contribution of prefrontal cortex. Biological Psychiatry, 60, 329-336.

Stefanacci, L., \& Amaral, D.G. (2002). Some observations on cortical inputs to the macaque monkey amygdala: an anterograde tracing study. Journal of Comparative Neurology, 451, 301-323.

Stroop, J.R. (1935). Studies of interference in serial verbal reactions. Journal of Experimental Psychology, 18, 643-662.
Urry, H.L., van Reekum, C.M., Johnstone, T., Kalin, N.H., Thurow, M.E., Schaefer, H.S., ... Davidson, R.J. (2006). Amygdala and ventromedial prefrontal cortex are inversely coupled during regulation of negative affect and predict the diurnal pattern of cortisol secretion among older adults. Journal of Neuroscience, 26 , 4415-4425.

Vermetten, E., Schmahl, C., Southwick, S.M., \& Bremner, J.D. (2007). Positron tomographic emission study of olfactory induced emotional recall in veterans with and without combat-related posttraumatic stress disorder. Psychopharmacology Bulletin, 40, 8-30.

Weiss, S.J. (2007). Neurobiological alterations associated with traumatic stress. Perspectives in Psychiatric Care, 43, 114-122.

Wessa, M., \& Flor, H. (2007). Failure of extinction of fear responses in posttraumatic stress disorder: evidence from second-order conditioning. American Journal of Psychiatry, 164, 1684-1692.

Williams, L.M., Kemp, A.H., Felmingham, K., Barton, M., Olivieri, G., Peduto, A., Gordon, E., \& Bryant, R.A. (2006). Trauma modulates amygdala and medial prefrontal responses to consciously attended fear. Neuroimage, 29, 347-357.

Yang, P., Wu, M.T., Hsu, C.C., \& Ker, J.H. (2004). Evidence of early neurobiological alternations in adolescents with posttraumatic stress disorder: a functional MRI study. Neuroscience Letters, 370, 13-18.

Yehuda, R., \& Ledoux, J. (2007). Response variation following trauma: a translational neuroscience approach to understand PTSD. Neuron, 56, 19-32.

Zubieta, J.K., Chinitz, J.A., Lombardi, U., Figure, L.M., Cameron, O.G., \& Liberzon, I. (1999). Medial frontal cortex involvement in PTSD symptoms: a SPECT study. Journal of Psychiatric Research, 33, 259-264. 